\title{
Short vs prolonged dual antiplatelet treatment upon endovascular stenting of peripheral arteries
}

This article was published in the following Dove Press journal:

Drug Design, Development and Therapy

6 October 2017

Number of times this article has been viewed

\author{
Mariya Kronlage' \\ Maximilian Wassmann' \\ Britta Vogel' \\ Oliver J Müller' \\ Erwin Blessing ${ }^{2}$ \\ Hugo Katus ${ }^{1,3}$ \\ Christian Erbel' \\ 'Department of Cardiology, Angiology \\ and Pneumology, University Hospital \\ Heidelberg, Heidelberg, ${ }^{2}$ SRH \\ Klinikum Karlsbad Langensteinbach, \\ Karlsbad, ${ }^{3}$ DZHK German Center \\ for Cardiovascular Research, \\ Partner Site Heidelberg/Mannheim, \\ Mannheim, Germany
}

\begin{abstract}
Introduction: Peripheral artery disease (PAD) is a highly prevalent disorder with a substantial economical burden. Dual antiplatelet treatment (DAPT) upon endovascular stenting to prevent acute thrombotic reocclusions is an universally accepted practice for postinterventional management of PAD patients. However, the optimal period of time for DAPT upon endovascular stenting is not known.
\end{abstract}

Methods: In the current nonrandomized, retrospective monocentric study, we evaluated the duration of DAPT upon endovascular stenting. A total of 261 endovascular SFA and iliac stenting procedures were performed on 214 patients and these patients were subdivided into a short (4-6 weeks) or a prolonged (8-12 weeks) DAPT regime group. More than $65 \%$ of the patients included were male, approximately $35 \%$ were diabetic, and $61 \%$ had a history of smoking. Of all the patients, $90 \%$ exhibited a Rutherford stage $2-3$, and approximately half of the patients had a moderateto-severe calcified target lesion with a length of $>13 \mathrm{~cm}$. Major safety end points were defined as any bleeding, compartment syndrome, and ischemic events. In addition to this, patency, all-cause mortality, as well as amputation were followed up over a period of 12 months upon intervention.

Results: Twelve months after endovascular stenting, primary patency in our cohort was comparable between the groups $(83.94 \%$ short vs $79.8 \%$ long DAPT, $P>0.05)$. Major bleeding occurred in 18 cases without any difference between the groups $(P>0.05)$. In addition, during the 12-month follow-up, $6(3.4 \%)$ patients in the short and $3(3.5 \%)$ in the prolonged DAPT regime suffered a stroke/transient ischemic attack $(P>0.05)$. In addition, there was no difference regarding mortality and amputation rate comparing short vs prolonged DAPT regime in a 12-month follow-up.

Conclusion: In the current cohort, prolonged DAPT after endovascular stenting had no beneficial effect on the outcome in a 12-month follow-up.

Keywords: peripheral artery disease, stent implantation, dual antiplatelet therapy, primary patency, endovascular therapy

\section{Abbreviations}

ABI, ankle-brachial index; BMS, bare metal stent; CAD, coronary artery disease; DAPT, dual antiplatelet treatment; DCB, drug-coated balloon; DES, drug-eluting stent; PAD, peripheral artery disease; POBA, plain old balloon angioplasty; SFA, superficial femoral artery; TIA, transient ischemic attack; TLR, target lesion revascularization.

\section{Introduction}

PAD is a manifestation of atherosclerotic vascular disease. Epidemiology studies show a total prevalence of $3 \%-10 \%$, which rises in the elderly over an age of 70 years to $15 \%-20 \% .^{1-3}$ Due to a steadily aging society and a growing number of patients with comorbidities such as diabetes, hypercholesterolemia, and renal insufficiency,
Correspondence: Mariya Kronlage and Pneumology, University Hospital Heidelberg, Im Neuenheimer Feld 410, 69120 Heidelberg, Germany Email mariya.kronlage@med.uniheidelberg.de (c) (1) (5) 2017 Kronlage et al. This work is published and licensed by Dove Medical Press Limited. The full terms of this license are available at https://www.dovepress.com/terms.php cc) hereby accept the Terms. Non-commercial uses of the work are permitted without any further permission from Dove Medical Press Limited, provided the work is properly attributed. For permission for commercial use of this work, please see paragraphs 4.2 and 5 of our Terms (https://www.dovepress.com/terms.php). 
the number of patients withaPAD is expected to further increase, ${ }^{4}$ thus causing growing costs for the health care system.

In addition, PAD is an independent indicator of cardiovascular morbidity and mortality $;^{5-8}$ both mortality and amputation risk are growing in parallel with Rutherford stage $(>63 \%$ chance of amputation within 4 years in Rutherford stage 6). ${ }^{9}$ Thus, prevention and adequate treatment of PAD is of crucial importance. Besides controlling cardiovascular risk factors, the optimization of blood flow by endovascular treatment or vascular operation is a central pillar of PAD care.

Endovascular treatment has gained increasing importance in recent years. ${ }^{3}$ Different endovascular techniques are available for the management of peripheral stenosis and/or occlusions. Standard interventional treatment options besides POBA are DCBs, BMSs, and DESs, as well as numerous atherectomy devices. In addition, stent implantation increases the patency rate compared to POBA and probably also to DCB, thus being often used particularly in long and/or calcified lesions. ${ }^{10,11}$

DAPT upon endovascular stenting is universally accepted to prevent subsequent thrombotic complications. However, the exact period of time in which a combination treatment of aspirin and clopidogrel should be applied upon stenting varies immensely among different centers. The current study aimed to compare whether the duration of DAPT has an impact on bleeding events, restenosis, patency, ischemic events, all-cause mortality, and amputation upon stent implantation in the iliac artery and SFA during a follow-up of 12 months. Patients were divided into 2 groups according to DAPT regime: a short (4-6 weeks) and a prolonged (8-12 weeks) group.

\section{Patients' collective and methods Study design}

The current investigation is a nonrandomized, retrospective monocentric study. A total of 261 endovascular SFA and iliac stenting procedures had been performed on 214 patients at the Department of Cardiology, Angiology and Pneumology, University Hospital Heidelberg, between 2004 and 2016. Patients with more than 1 intervention were only included in the current study, if the second intervention was performed on the other lower extremity and not in the 12-month observation period of the first intervention. Follow-up examinations including clinical visit, ABI measurement, as well as Doppler sonography of the affected limb were performed immediately after, as well as 1, 3, 6, and 12 months after, the intervention. The study was approved by the local ethical committee at the University Hospital Heidelberg as a part of the Heidelberg
Registry for PAD (S-331/2013) and was performed in accordance with the ethical requirements as stated in the Declaration of Helsinki. Informed consent was waived by the local ethics committee due to the retrospective design of the study. Since only the responsible physicians had access to non-anonymized patient data, absolute confidentiality of patient information was ensured.

The selection of the antiplatelet therapy duration was dependent on the interventionalist who approved the indication for an angiography. One interventionalist always used the prolonged regime, while the others primarily used the short-term antiplatelet therapy regime. The interventions were performed together to exclude a bias of the experience of the interventionalist.

Safety end points were defined as any procedure-dependent local vascular complication: arteriovenous fistula, aneurysm, and local bleeding in the area of the puncture side; in addition to that, systemic bleeding, compartment syndrome, and ischemic events (stroke, TIA) upon a 12-month follow-up were evaluated. Efficacy end points included clinical-relevant restenosis, patency, all-cause mortality, and amputation.

Primary patency was defined as freedom from significant restenosis of target lesion ( $>50 \%$ reocclusion) as measured by Doppler ultrasound during a 12-month follow-up. Secondary patency resembled patency of the target lesion after (re)occlusion intervention of the index lesion.

Clinical symptoms of the patients included in the study were evaluated in terms of the Rutherford classification used for staging patients with PAD. ${ }^{12}$ Stage 0 includes asymptomatic patients. Depending on the symptoms, PAD patients were classified in mild (stage 1), moderate (stage 2), or severe (stage 3 ) stage. Stage 4 PAD patients had rest pain, and stage 5 and 6 ulcerations.

\section{Lesion calcification assessment}

Assessment of target lesion characteristics was performed by 4 independent examiners (CE, MK, MA, and IS). Low calcification grade was defined as no or only isolated plaques, up to $50 \%$ circumferential lumen constringency by a plaque was defined as moderate, and $>50 \%$ was referred to as severe.

\section{Interventional treatment methods}

All patients received an intraarterial bolus of 2500 IU heparin after a $6 \mathrm{~F}$ sheath placement. During intervention, all patients received additional 2500 IU heparin. After crossing the culprit lesion with a guide wire, the lesions were dilated with an adequate balloon diameter for the treated vessel, followed by a BMS implantation. An optimal balloon pressure is elemental 
to break calcified lesions, to achieve long-term patency, and to treat dissection without the risk of artery wall perforation.

The decision for stent implantation was made by the interventionalists after angiography, depending on the extension of the occlusion, presence of recoil due to severe calcification, or blood flow limiting dissection. The type of stent depended on the preference of the interventionalists. All patients received $500 \mathrm{mg}$ aspirin during the intervention and $300 \mathrm{mg}$ clopidogrel after stent implantation at the end of the procedure. Out of 261 cases, 175 received a short-term antiplatelet therapy (4-6 weeks), and 86 a prolonged DAPT regime (8-12 weeks) of aspirin (100 mg/daily) and clopidogrel (75 mg daily).

\section{Statistical analysis}

Chi-square tests were used to compare categorical data. Continuous variables were represented as mean \pm SD. $t$-Test was used to compare means when variables were normally distributed. Kaplan-Meier curves were drawn to present survival data, and log-rank tests were used to assess differences in time-to-event end points. $P$-values of $<0.05$ were considered statistically significant. Data analysis was performed using IBM SPSS, version 22.0 software.

\section{Results}

\section{Patient characteristics}

A total of 214 patients underwent 261 consecutive interventional revascularization procedures including endovascular stenting of the SFA and iliac arteries between 2004 and 2016 at the Department of Cardiology, Angiology and Pneumology, University Hospital Heidelberg.

General data of the patients' collective including gender, age, weight, and height, as well as relevant cardiovascular risk factors and comorbidities, are summarized in Tables 1 and 2 . In both groups, the majority of patients were admitted with the leading diagnosis of chronic progressive claudication (duration of symptoms was more than 2 weeks), corresponding to Rutherford stage 2-3 (Table 3 ). The rest of

Table I Major demographic characteristics of the study population in terms of gender, age, weight, and height ( $n=214$ patients)

\begin{tabular}{lllll}
\hline $\begin{array}{l}\text { Patients' } \\
\text { characteristics }\end{array}$ & Total & 4-6 weeks & $8-12$ weeks & P-value \\
\hline Male, $\mathrm{n}(\%)$ & $143(66.8)$ & $95(66.4)$ & $48(60.6)$ & $>0.05$ \\
Female, $\mathrm{n}(\%)$ & $71(33.2)$ & $48(33.6)$ & $23(32.4)$ & \\
Age, mean \pm SD (years) & $68.7 \pm 9.6$ & $67.9 \pm 9.2$ & $70.1 \pm 9.0$ & $>0.05$ \\
Weight, mean \pm SD (kg) & $78.1 \pm 15.4$ & $77.5 \pm 15.1$ & $79.1 \pm 15.8$ & $>0.05$ \\
Height, mean \pm SD (cm) & $170.9 \pm 8.6$ & $171.2 \pm 8.2$ & $170.2 \pm 8.9$ & $>0.05$ \\
BMI $\left(\mathrm{kg} / \mathrm{m}^{2}\right)$ & 27.0 & 27.0 & 27.3 & $>0.05$ \\
\hline
\end{tabular}

Abbreviation: BMl, body mass index. the patients had acute or subacute symptoms (claudication, palor, skin ulceration), with duration of less than 2 weeks. In short DAPT and prolonged DAPT groups, $16.0 \%$ and $17.4 \%$ of patients, respectively, received additional long-term anticoagulation therapy mostly due to preexisting atrial fibrillation or thrombotic nature of the arterial occlusion, or within the frame of a conservative therapy attempt (Table 3).

\section{Lesion characteristics and safety of the interventional procedure}

The majority of patients in both groups displayed mild-tomoderate calcification (69.1\% vs 66.2\%, Table 4), and most of the lesions were characterized by a significant length: 12.9 \pm 9.7 and $14.4 \pm 8.1 \mathrm{~cm}$, respectively, (Table 4). Percutaneous transluminal angioplasty was performed in the vast majority ( $89.7 \%$ short DAPT group, $97.7 \%$ prolonged DAPT group, ns, Table 4) with a corresponding balloon pressure of an average $10.1 \pm 4.4$ bar. The prolonged DAPT group had a significantly longer cumulative balloon dilatation time of 58.5 seconds compared to 41.5 seconds of the short DAPT group $(P<0.05$, Table 4$)$.

\section{Safety of the interventional procedure during follow-up of 12 months}

In our patients' collective, during the follow-up period of 12 months, a total of 18 severe bleeding occasions occurred: $\mathrm{n}=13(7.4 \%)$ in the short DAPT group and $\mathrm{n}=5(5.8 \%)$ in the prolonged DAPT group (1 intracranial, 1 compartment, 1 relevant intramuscular hematoma [thigh], 15 gastrointestinal). No difference was seen between the groups (Figure 1). Notably, only 4 out of 18 patients with relevant bleeding had received concomitant anticoagulation. Moreover, minor bleeding and/or periprocedural-dependent local vascular complication took place $4.6 \%$ in the short- and $5.8 \%$ in the long-term DAPT ( $P>0.05$, Table 4). Peripheral embolizations occurred in only 2 patients $(0.8 \%)$.

A total of 14 patients in the short and 7 in the prolonged DAPT group had a history of stroke/TIA (Table 2 ). In addition, during the follow-up of 12 months, $6(3.4 \%)$ patients in the short-term and $3(3.5 \%)$ in the long-term DAPT regime suffered a stroke/TIA with no statistical difference (Figure 1).

\section{Primary and secondary patency}

Twelve months after endovascular stenting of the SFA and the iliac vessels, there was no difference in primary patency in both groups $(83.9 \%$ vs $79.8 \%, P>0.05$, Figure $2 \mathrm{~A}$ and $\mathrm{B})$, irrespective of the length and/or calcification grade of the treated stenosis or occlusion (data not shown). Secondary 
Table 2 Major cardiovascular risk factors and comorbidities ( $\mathrm{n}=2 \mathrm{I} 4$ patients)

\begin{tabular}{lllll}
\hline & Total & 4-6 weeks & 8-I2 weeks & P-value \\
\hline Smoking (active and history of smoking), $\mathrm{n}(\%)$ & $132(61.7)$ & $85(61.6)$ & $47(61.9)$ & $>0.05$ \\
Arterial hypertension, $\mathrm{n}(\%)$ & $179(83.6)$ & $1 \mathrm{I}(81.6)$ & $67(88.2)$ & $>0.05$ \\
Diabetes, $\mathrm{n}(\%)$ & $82(38.3)$ & $46(33.3)$ & $36(47.4)$ & $>0.05$ \\
Coronary artery disease, $\mathrm{n}(\%)$ & $96(44.9)$ & $64(46.4)$ & $32(42.1)$ & $>0.05$ \\
COPD, $\mathrm{n}(\%)$ & $21(9.8)$ & $5(6.6)$ & $16(11.6)$ & $>0.05$ \\
Atrial fibrilation, $\mathrm{n}(\%)$ & $22(10.3)$ & $7(9.2)$ & $15(10.9)$ & $>0.05$ \\
Creatinine, mean \pm SD (mg/dL) & $1.4 \pm 1.5$ & $1.3 \pm 15$ & $4.5 \pm 1.5$ & $>0.05$ \\
Urea, mean \pm SD (mg/dL) & $45.6 \pm 26.9$ & $46.1 \pm 31.0$ & $44.8 \pm 19.8$ & $7(8.4)$ \\
History of stroke/TIA, $\mathrm{n}(\%)$ & $21(8.0)$ & $14(8.0)$ & & $>0.05$ \\
\hline
\end{tabular}

Abbreviation: TIA, transient ischemic attack.

patency was $>90 \%$ in both groups, showing no difference between the short and prolonged DAPT treatment regimes $(P>0.05$, Figure 3$)$. Notably, the patients with or without anticoagulation did not differ between primary and secondary patency, amputation, and all-cause mortality.

\section{No difference between the DAPT regimes in the prevention of major end points}

Kaplan-Meier analysis was performed in order to trace overall and amputation-free survival during a 1-year follow-up (Figure 4A and B). A total of 4 patients died in the short and 2 in the prolonged DAPT group $(P<0.05)$; none of the death cases were related to the endovascular procedure. The causes of death were prolonged cardiogenic shock in 4 cases, acute arteria cerebri media infarction in 1 case, and metformin-induced lactate acidosis in acute-on-chronic renal failure (1 case).

Amputations occurred in 3 cases ( 1 patient in the short and 2 in the prolonged DAPT group, $P>0.05$ ): In only 1 case, the amputation was performed due to a postinterventional complete thrombotic occlusion of the lower extremity, resistant to lysis and further endovascular revascularization treatment.

Table 3 Symptom characterization in terms of Rutherford stage, duration of symptoms, and anticoagulation prior to revascularization ( $n=26$ I cases)

\begin{tabular}{|c|c|c|c|c|}
\hline & Total & 4-6 weeks & $8-12$ weeks & $P$-value \\
\hline Rutherford stage, n (\%) & & & & $>0.05$ \\
\hline 2 & $157(60.2)$ & $105(60.0)$ & $52(60.5)$ & \\
\hline 3 & $92(35.3)$ & $64(36.6)$ & $28(32.6)$ & \\
\hline 4 & $4(1.5)$ & $2(I . I)$ & $2(2.3)$ & \\
\hline 5 & $4(1.5)$ & $2(I . I)$ & $2(2.3)$ & \\
\hline 6 & $4(1.5)$ & $\mathrm{I}(0.6)$ & $3(3.1)$ & \\
\hline $\begin{array}{l}\text { Symptoms' duration } \\
>2 \text { weeks, } \mathrm{n}(\%)\end{array}$ & I7I (65.5) & $116(66.3)$ & $55(63.9)$ & $>0.05$ \\
\hline Anticoagulation, $\mathrm{n}(\%)$ & $43(16.5)$ & $28(16.0)$ & $15(17.4)$ & $>0.05$ \\
\hline
\end{tabular}

A second major amputation needed to be performed due to a super-infection and a beginning sepsis of a patient with a Rutherford stage 4. A third amputation was performed at an external hospital, and no information was available regarding the exact reason for amputation.

By separating the patients' collective according to the lesion location, iliac vessels, and SFA, the study demonstrated no difference between the groups in terms of primary and secondary patency, amputation, all-cause mortality, and ABI measurement.

\section{Substantial $A B I$ improvement upon intervention in both groups}

Prior to intervention, both patient groups presented with significantly reduced ABI values: $0.6 \pm 0.2$ and $0.6 \pm 0.2$. Immediately after intervention, the ABI values significantly improved $(0.9 \pm 0.2$ and $0.8 \pm 0.2, P<0.05)$. These results remained stable and significantly better than before the intervention over the next 12 months $(P<0.05$, respectively, Figure 5).

\section{Discussion}

Despite the increasing number of patients receiving endovascular stent due to a progressive PAD, the knowledge regarding postinterventional management, and more specifically DAPT after stent implantation, is still markedly limited. The DAPT used in clinical routine is mainly extrapolated to data on DAPT after coronary artery interventions. ${ }^{13,14}$

Heiss et al published a randomized trial of 199 patients after angioplasty in the femoropopliteal location. ${ }^{15}$ The patients were divided into 3 groups, dipyridamol $75 \mathrm{mg}$ together with a high ASS dosage of $330 \mathrm{mg}$ or a low ASS concentration of $100 \mathrm{mg}$ or placebo. The study demonstrated that dipyridamol $75 \mathrm{mg}$ plus ASS $330 \mathrm{mg}$ showed a significantly better patency compared to placebo. No difference was seen for dipyridamol $75 \mathrm{mg}$ plus ASS $100 \mathrm{mg}$ vs placebo. 
Table 4 Target lesion characterization: localization, extension, grade of calcification, presence of thrombotic occlusion, PTA, and corresponding mean duration of dilatation and balloon pressure, as well as major peri-interventional complications

\begin{tabular}{|c|c|c|c|c|}
\hline & Total & 4-6 weeks & $8-12$ weeks & $P$-value \\
\hline Target lesion iliac artery, $\mathrm{n}(\%)$ & $63(24.1)$ & $44(25.1)$ & $19(22.1)$ & $>0.05$ \\
\hline Target lesion SFA, n (\%) & $214(82.0)$ & $134(76.6)$ & $69(80.2)$ & $>0.05$ \\
\hline Length of occlusion, mean $\pm \mathrm{SD}(\mathrm{cm})$ & $13.6 \pm 9.0$ & $12.9 \pm 9.7$ & $14.4 \pm 8.1$ & $>0.05$ \\
\hline Total occlusion, $\mathrm{n}(\%)$ & $115(44.1)$ & $78(44.6)$ & $37(37.2)$ & $>0.05$ \\
\hline \multicolumn{5}{|l|}{ Calcification score, $\mathrm{n}(\%)$} \\
\hline None & $17(6.5)$ & $5(2.9)$ & $12(14.0)$ & $<0.05$ \\
\hline Mild & $90(34.5)$ & $58(33.1)$ & $32(37.2)$ & $>0.05$ \\
\hline Moderate & $88(33.7)$ & $63(36.0)$ & $25(29.0)$ & $>0.05$ \\
\hline Severe & $57(21.8)$ & $45(25.7)$ & $12(14.0)$ & $<0.01$ \\
\hline Thrombotic occlusion, n (\%) & $24(9.2)$ & $13(7.7)$ & II (I2.8) & $>0.05$ \\
\hline PTA, n (\%) & $24 I(92.3)$ & $157(89.7)$ & $84(97.7)$ & $>0.05$ \\
\hline Balloon pressure, mean \pm SD (bar) & $10.1 \pm 4.4$ & $10.5 \pm 4.6$ & $9.8 \pm 4.2$ & $>0.05$ \\
\hline Balloon dilatation time, mean \pm SD (seconds) & $50.0 \pm 40.1$ & $41.5 \pm 26.0$ & $58.5 \pm 54.1$ & $<0.05$ \\
\hline Minor bleeding, periprocedural-dependent & $13(5.0)$ & $8(4.6)$ & $5(5.8)$ & $>0.05$ \\
\hline \multicolumn{5}{|l|}{ local vascular complication, n (\%) } \\
\hline Peri-interventional embolization, $\mathrm{n}(\%)$ & $2(0.8)$ & $2(1.1)$ & $0(0.0)$ & $>0.05$ \\
\hline Hospitalization duration, mean \pm SD (days) & $1.5 \pm 2.0$ & $1.4 \pm 1.6$ & $1.7 \pm 2.3$ & $>0.05$ \\
\hline
\end{tabular}

Abbreviations: PTA, percutaneous transluminal angioplasty; SFA, superficial femoral artery.

Another prospective, double-blind study with 223 patients investigated DAPT after iliofemoral angioplasty upon a 12-month follow-up. ${ }^{16}$ The patients were grouped into dipyridamol $400 \mathrm{mg}$ together with ASS $50 \mathrm{mg}$ and placebo. The study found no difference between the groups. Only in the iliac artery, the placebo group had more interventions. Tepe et al provided the only prospective, randomized, doubleblind placebo-controlled clinical trial so far that investigated antiplatelet therapy after peripheral artery BMS implantation in a cohort of 80 patients. ${ }^{17}$ The study compared mono treatment of aspirin vs DAPT of aspirin plus clopidogrel. An advantage for DAPT vs aspirin alone was found in terms

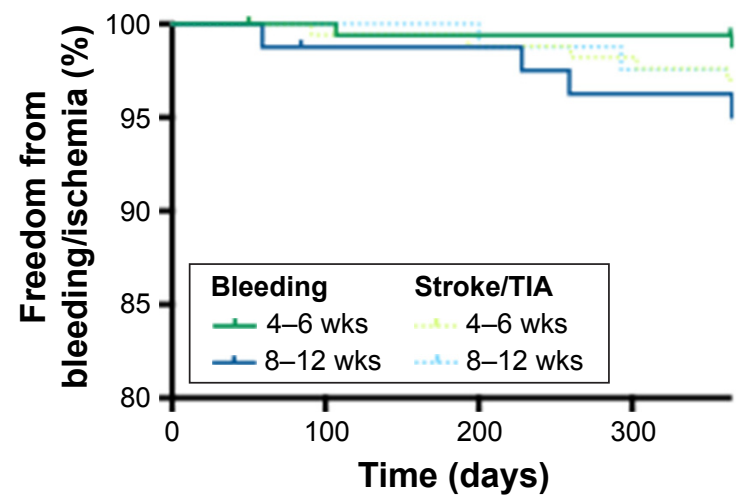

Figure I Kaplan-Meier analysis of combined safety end points 12 months upon revascularization (systemic bleeding, as well as ischemic events such as stroke/TIA). Notes: Bleeding in the short DAPT group is indicated by the solid green line, and in the prolonged DAPT group by the solid blue line. Stroke/TIA in the short DAPT group is indicated by the dotted green line, and in the prolonged DAPT group by the dotted blue line. All $P$-values are $>0.05$.

Abbreviations: TIA, transient ischemic attack; DAPT, dual antiplatelet treatment. of TLR ( 2 vs 8 patients, $P=0.04$ ), but was not associated with increased minor bleeding complications. However, due to the limited number of patients and TLR, the usage of molecular surrogates as primary end points (local concentrations of platelet activation markers $\beta$-thromboglobulin and CD40L), and the observation period of only 6 months, the informative value as well as the clinical relevance of this study is significantly limited. In our cohort, we compared different DAPT regimes in terms of their safety and efficacy upon BMS implantation. To the best of our knowledge, this is the first study comparing the duration of DAPT after peripheral artery stent implantation. The study showed no difference in terms of primary and secondary patency, amputation, survival, and clinical outcome between both groups. In addition, major safety end points did not differ between both treatment regimes. Thus, 4 weeks of DAPT after BMS implantation seems to be not inferior in a real-world patient collective.

Different interventional treatment options are available for the atherosclerotic diseased iliac and femoral arteries. POBA is increasingly being replaced by DCB with significantly higher patency rates and a DAPT regime of at least 4 weeks. ${ }^{18-22}$ Primary patency of the published studies was on average $80 \%-90 \%$ in short and primarily mildly calcified lesions. However, DCB seems to be less effective in complex stenosis as shown by Schmidt et al with primary patency of $53 \%$ after 24 months. ${ }^{11}$ Several studies investigated peripheral artery stent implantation outcome after 12 months with a DAPT therapy regime of 4-6 weeks. The re-intervention rate 

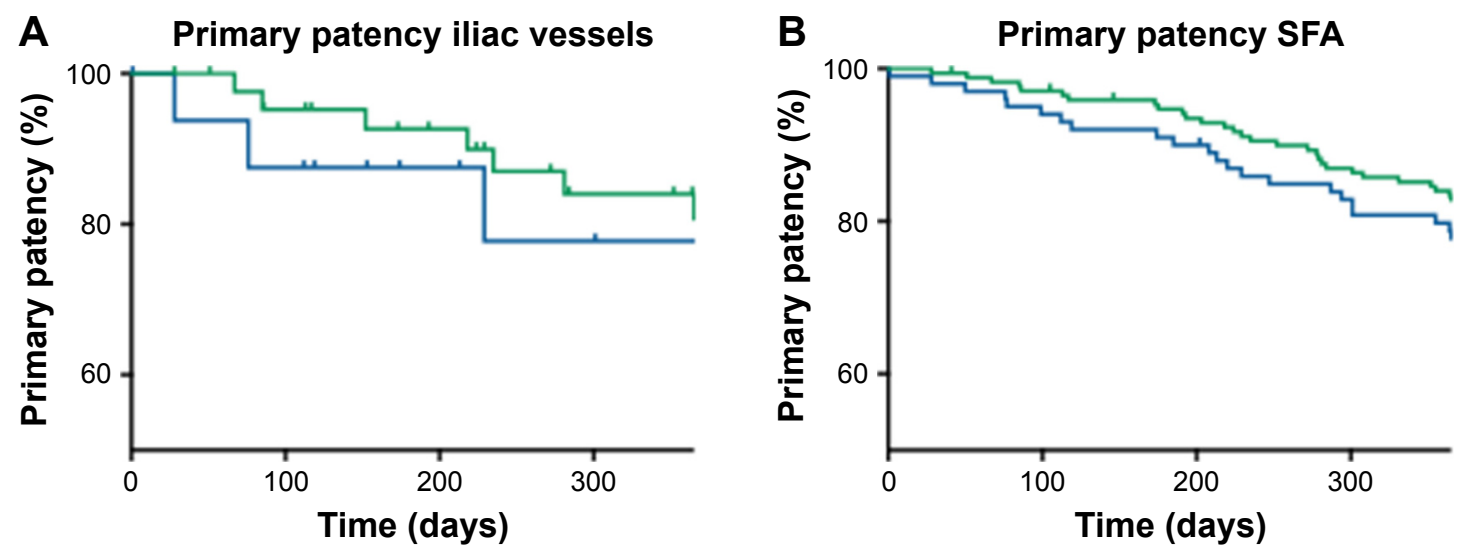

Figure 2 Kaplan-Meier analysis of primary patency 12 months upon index revascularization, separated according to lesion location: (A) iliac vessels and (B) SFA. Notes: Short DAPT group is indicated by the solid green line, and prolonged DAPT group by the solid blue line. P-values are $>0.05$ for both.

Abbreviations: SFA, superficial femoral artery; DAPT, dual antiplatelet treatment.

in complex lesions was $14.2 \%$ in the Supera stent-, $28.3 \%$ in the EverFlex-, $14.9 \%$ in the EPIC self-expanding nitinol stent-, and $18.3 \%$ in the SMART-study. ${ }^{23-26}$ Furthermore, drug-coated stent studies revealed low re-intervention rates with a TLR of $4 \%$ in the MAJESTIC trial (single arm) and $9.5 \%$ in the Zilver PTX trial. ${ }^{27,28}$ The treated lesions in the reported studies were predominantly short $(\sim 7 \mathrm{~cm})$, whereas most of the lesions in the present study were both longer and of a moderate-to-severe calcification grade (Table 4) that could possibly explain a re-intervention rate of $16 \%$ in the short-term and $23.5 \%$ in the long-term DAPT regime group. Taking the results from previous reports and our present study into consideration, BMS implantations appear to be a valuable treatment option in patients with symptomatic peripheral artery stenosis, both in short and in long calcified lesions.

Antiplatelet therapy is generally recommended for all patients with PAD to improve event-free survival, both as a primary and secondary prevention measure upon endovascular interventions. ${ }^{29-33}$ The available data regarding safety and

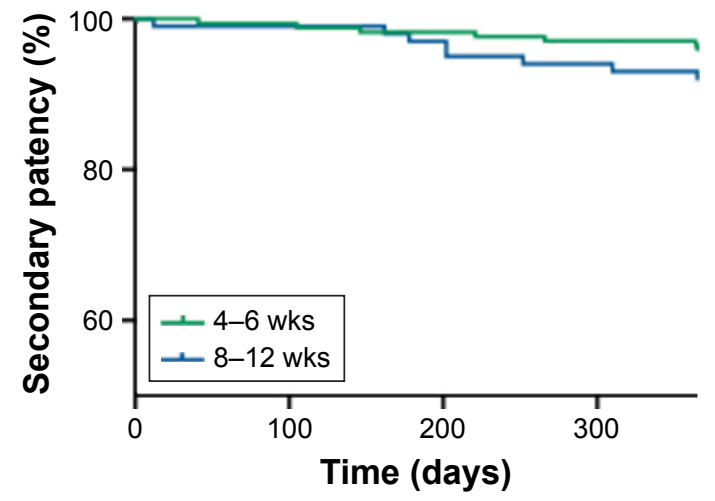

Figure 3 Kaplan-Meier analysis of secondary patency 12 months upon primary revascularization.

Notes: Short DAPT group is indicated by the solid green line, and prolonged DAPT group by the solid blue line. $P>0.05$.

Abbreviations: SFA, superficial femoral artery; DAPT, dual antiplatelet treatment. efficacy of different antiplatelet agents in the treatment of PAD are very heterogeneous. Recently, 3 publications aimed to investigate the impact of ticagrelor in PAD patients. ${ }^{34-36}$ Ticagrelor is known to have beneficial effects in patients with an acute coronary syndrome and as a secondary prevention in patients with $\mathrm{CAD} .{ }^{37,38}$ In patients with a PAD after a myocardial infarction, DAPT with ticagrelor and aspirin vs aspirin reduced the rate of cardiovascular mortality, stroke, and myocardial infarction. ${ }^{36}$ However, it remains to be elucidated whether ticagrelor and aspirin is superior to clopidogrel alone, since clopidogrel alone showed a significant risk reduction of $23.8 \%$ for cardiovascular complications and bleeding compared to aspirin in patients with $\mathrm{PAD}$ and $\mathrm{CAD}$ in the CAPRIE trial..$^{32}$ In addition, in symptomatic PAD patients with and without an intervention, Hiatt et al demonstrated that ticagrelor vs clopidogrel showed no advantages regarding the composite end point of cardiovascular death, myocardial infarction, or ischemic stroke. ${ }^{35,36}$ Focused on ischemic stroke, the study demonstrated a significant reduction in the ticagrelor vs clopidogrel group (1.9\% vs $2.4 \%)$. ${ }^{35}$ Thus, based on the large studies with different effects of ticagrelor in CAD and PAD patients, it appears that both diseases have 2 different entities and the results of studies in the field of CAD should be interpreted with caution, when transferred to PAD.

\section{Limitations}

There are several limitations in the current study. First, the current study is a monocentric, nonrandomized retrospective registry; thus, results need to be interpreted carefully. In addition, only a limited number of selected patients with primarily complicated lesions were included; thus, the data cannot be transferred to other lesion characteristics and patients' collectives. Moreover, we investigated patients upon endovascular stenting; thus, the data cannot 

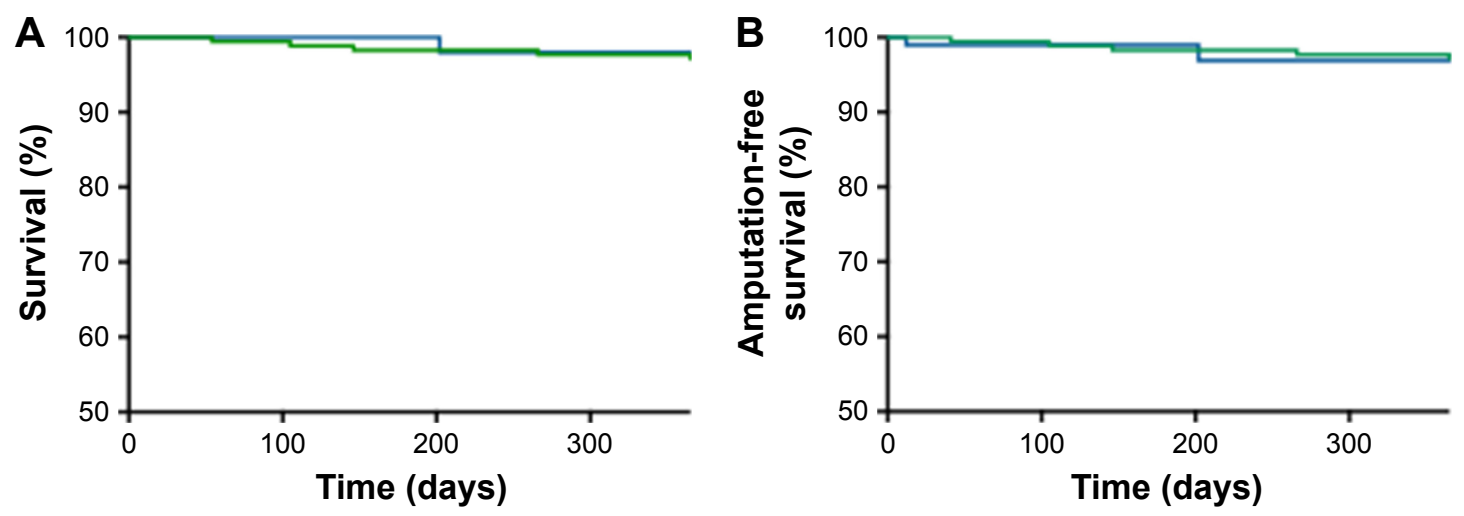

+4-6 wks $\leftarrow$ 8-12 wks

Figure 4 (A) Overall survival I 2 months upon primary revascularization was analyzed using Kaplan-Meier.

Notes: Short DAPT group is indicated by the solid green line, and prolonged DAPT group by the solid blue line. P $>0.05$. (B) Kaplan-Meier analysis of amputation-free survival 12 months upon primary revascularization. Short DAPT group is indicated by the solid green line, and prolonged DAPT group by the solid blue line. P $>0.05$. Abbreviation: DAPT, dual antiplatelet treatment.

be extrapolated to patients upon normal angioplasty, DCB, DES, or atherectomy. Furthermore, we evaluated the different lesion locations, iliac artery and SFA, with known divergent outcomes within 1 study.

However, the main focus of the current study was safety and efficacy in a real-world patients' collective; in our collective, we could detect no significant differences upon stenting of the iliac vessels vs stenting of the SFA - neither in terms of safety and efficacy, nor in terms of outcome; those results did not change over the years (2004-2010) vs (2011-2016).

\section{Conclusion}

The current study provides a first rationale comparison between short- and long-term DAPT regime after BMS implantation in peripheral arteries. Short DAPT seems to be not inferior to prolonged DAPT regime in terms of safety and

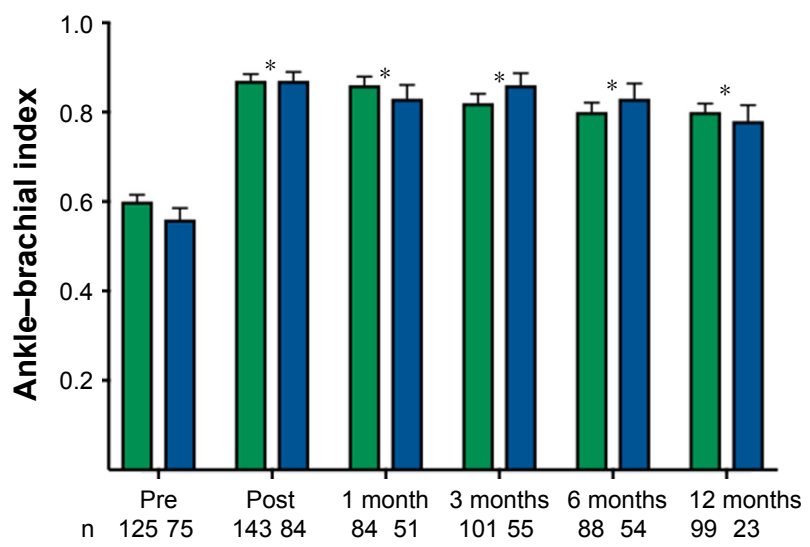

Figure $5 \mathrm{ABI}$ measurements before, immediately after, as well as I, 3, 6, and 12 months after intervention.

Notes: Short DAPT group is indicated by the green bars, and prolonged by the blue bars. Bar graph represents mean $+\mathrm{SD}$. $* P<0.05$

Abbreviations: $\mathrm{ABI}$, ankle-brachial index; DAPT, dual antiplatelet treatment. efficacy after peripheral interventions with BMS implantation in a 12-month follow-up, but additional studies are needed to further investigate these findings.

\section{Acknowledgments}

The authors are thankful to Dr Ingo Staudacher (IS) and Dr Mohammad Akhavanpoor (MA) for independently assessing the angiography films in this study. The abstract of this paper was presented at the international Leipzig Interventional Course (LINC) conference on January 24-26, 2017, as a poster with interim findings.

\section{Disclosure}

The authors report no conflicts of interest in this work.

\section{References}

1. Criqui MH, Fronek A, Barrett-Connor E, Klauber MR, Gabriel S, Goodman D. The prevalence of peripheral arterial disease in a defined population. Circulation. 1985;71(3):510-515.

2. Diehm C, Schuster A, Allenberg JR, et al. High prevalence of peripheral arterial disease and co-morbidity in 6880 primary care patients: crosssectional study. Atherosclerosis. 2004;172(1):95-105.

3. Gerhard-Herman MD, Gornik HL, Barrett C, et al. 2016 AHA/ACC guideline on the management of patients with lower extremity peripheral artery disease: executive summary: a report of the American College of Cardiology/American Heart Association Task Force on Clinical Practice Guidelines. Circulation. 2017;135:e686-e725.

4. Heikkinen M, Salmenperä M, Lepäntalo A, Lepäntalo M. Diabetes care for patients with peripheral arterial disease. Eur J Vasc Endovasc Surg. 2007;33(5):583-591.

5. Espinola-Klein C, Rupprecht HJ, Bickel C, et al; AtheroGene Investigators. Different calculations of ankle-brachial index and their impact on cardiovascular risk prediction. Circulation. 2008;118(9):961-967.

6. Antithrombotic Trialists' Collaboration. Collaborative meta-analysis of randomised trials of antiplatelet therapy for prevention of death, myocardial infarction, and stroke in high risk patients. BMJ. 2002; 324(7329):71-86.

7. Golomb BA, Dang TT, Criqui MH. Peripheral arterial disease: morbidity and mortality implications. Circulation. 2006;114(7):688-699. 
8. Diehm C, Lange S, Darius H, et al. Association of low ankle brachial index with high mortality in primary care. Eur Heart J. 2006;27(14): 1743-1749.

9. Reinecke H, Unrath M, Freisinger E, et al. Peripheral arterial disease and critical limb ischaemia: still poor outcomes and lack of guideline adherence. Eur Heart J. 2015;36(15):932-938.

10. Laird JR, Katzen BT, Scheinert D, et al; RESILIENT Investigators. Nitinol stent implantation vs. balloon angioplasty for lesions in the superficial femoral and proximal popliteal arteries of patients with claudication: three-year follow-up from the resilient randomized trial. J Endovasc Ther. 2012;19(1):1-9.

11. Schmidt A, Piorkowski M, Görner H, et al. Drug-coated balloons for complex femoropopliteal lesions: 2-year results of a real-world registry. JACC Cardiovasc Interv. 2016;9(7):715-724.

12. Hardman RL, Jazaeri O, Yi J, Smith M, Gupta R. Overview of classification systems in peripheral artery disease. Semin Intervent Radiol. 2014;31(4):378-388.

13. Levine GN, Bates ER, Blankenship JC, et al. 2011 ACCF/AHA/ SCAI guideline for percutaneous coronary intervention: a report of the American College of Cardiology Foundation/American Heart Association Task Force on Practice Guidelines and the Society for Cardiovascular Angiography and Interventions. Circulation. 2011;124(23): e574-e651.

14. Windecker S, Kolh P, Alfonso F, et al. 2014 ESC/EACTS Guidelines on myocardial revascularization: the Task Force on Myocardial Revascularization of the European Society of Cardiology (ESC) and the European Association for Cardio-Thoracic Surgery (EACTS) developed with the special contribution of the European Association of Percutaneous Cardiovascular Interventions (EAPCI). Eur Heart J. 2014;35(37): 2541-2619.

15. Heiss HW, Just H, Middleton D, Deichsel G. Reocclusion prophylaxis with dipyridamole combined with acetylsalicylic acid following PTA. Angiology. 1990;41(4):263-269.

16. Platelet inhibition with ASA/dipyridamole after percutaneous balloon angioplasty in patients with symptomatic lower limb arterial disease. A prospective double-blind trial. Study group on pharmacological treatment after PTA. Eur J Vasc Surg. 1994;8(1):83-88.

17. Tepe G, Bantleon R, Brechtel K, et al. Management of peripheral arterial interventions with mono or dual antiplatelet therapy - the mirror study: a randomised and double-blinded clinical trial. Eur Radiol. 2012; 22(9):1998-2006.

18. Werk M, Langner S, Reinkensmeier B, et al. Inhibition of restenosis in femoropopliteal arteries: paclitaxel-coated versus uncoated balloon: femoral paclitaxel randomized pilot trial. Circulation. 2008;118(13): 1358-1365.

19. Zeller T, Beschorner U, Pilger E, et al. Paclitaxel-coated balloon in infrapopliteal arteries: 12-month results from the BIOLUX P-II randomized trial (BIOTRONIK's-first in man study of the Passeo-18 LUX drug releasing PTA balloon catheter vs. the uncoated Passeo-18 PTA balloon catheter in subjects requiring revascularization of infrapopliteal arteries). JACC Cardiovasc Interv. 2015;8(12):1614-1622.

20. Schroeder H, Meyer DR, Lux B, Ruecker F, Martorana M, Duda S. Two-year results of a low-dose drug-coated balloon for revascularization of the femoropopliteal artery: outcomes from the illumenate firstin-human study. Catheter Cardiovasc Interv. 2015;86(2):278-286.

21. Tepe G, Laird J, Schneider P, et al; IN.PACT SFA Trial Investigators. Drug-coated balloon versus standard percutaneous transluminal angioplasty for the treatment of superficial femoral and popliteal peripheral artery disease: 12-month results from the IN.PACT SFA randomized trial. Circulation. 2015;131(5):495-502.

22. Cassese S, Byrne RA, Ott I, et al. Paclitaxel-coated versus uncoated balloon angioplasty reduces target lesion revascularization in patients with femoropopliteal arterial disease: a meta-analysis of randomized trials. Circ Cardiovasc Interv. 2012;5(4):582-589.
23. George JC, Rosen ES, Nachtigall J, VanHise A, Kovach R. Supera interwoven nitinol stent outcomes in above-knee interventions (SAKE) study. J Vasc Interv Radiol. 2014;25(6):954-961.

24. Diehl SJ, Gerblich F, Jochum S, et al. Twelve-month results of the everflex stent in the superficial femoral artery. J Vasc Interv Radiol. 2012;23(10):1317-1322.

25. Werner M, Piorkowski M, Thieme M, et al. Summit registry: one-year outcomes after implantation of the epic self-expanding nitinol stent in the femoropopliteal segment. J Endovasc Ther. 2013;20(6):759-766.

26. Chalmers N, Walker PT, Belli AM, et al. Randomized trial of the smart stent versus balloon angioplasty in long superficial femoral artery lesions: the super study. Cardiovasc Intervent Radiol. 2013;36(2): 353-361.

27. Müller-Hülsbeck S, Keirse K, Zeller T, Schroë H, Diaz-Cartelle J. Twelve-month results from the majestic trial of the eluvia paclitaxeleluting stent for treatment of obstructive femoropopliteal disease. J Endovasc Ther. 2016;23(5):701-707.

28. Dake MD, Ansel GM, Jaff MR, et al; Zilver PTX Investigators. Paclitaxel-eluting stents show superiority to balloon angioplasty and bare metal stents in femoropopliteal disease: twelve-month Zilver PTX randomized study results. Circ Cardiovasc Interv. 2011;4(5): 495-504.

29. European Stroke Organisation, Tendera M, Aboyans V, Bartelink ML, et al; ESC Committee for Practice Guidelines. ESC guidelines on the diagnosis and treatment of peripheral artery diseases: document covering atherosclerotic disease of extracranial carotid and vertebral, mesenteric, renal, upper and lower extremity arteries: the Task Force on the Diagnosis and Treatment of Peripheral Artery Diseases of the European Society of Cardiology (ESC). Eur Heart J. 2011;32(22):2851-2906.

30. Bhatt DL, Fox KA, Hacke W, et al; CHARISMA Investigators. Clopidogrel and aspirin versus aspirin alone for the prevention of atherothrombotic events. N Engl J Med. 2006;354(16):1706-1717.

31. Antithrombotic Trialists' (ATT) Collaboration, Baigent C, Blackwell L, Collins R, et al. Aspirin in the primary and secondary prevention of vascular disease: collaborative meta-analysis of individual participant data from randomised trials. Lancet. 2009;373(9678):1849-1860.

32. CAPRIE Steering Committee. A randomised, blinded, trial of clopidogrel versus aspirin in patients at risk of ischaemic events (CAPRIE). CAPRIE Steering Committee. Lancet. 1996;348(9038):1329-1339.

33. Cacoub PP, Bhatt DL, Steg PG, Topol EJ, Creager MA; CHARISMA Investigators. Patients with peripheral arterial disease in the charisma trial. Eur Heart J. 2009;30(2):192-201.

34. Jones WS, Baumgartner I, Hiatt WR, et al; International Steering Committee and Investigators of the EUCLID Trial. Ticagrelor compared with clopidogrel in patients with prior lower extremity revascularization for peripheral artery disease. Circulation. 2017;135(3):241-250.

35. Hiatt WR, Fowkes FG, Heizer G, et al; EUCLID Trial Steering Committee and Investigators. Ticagrelor versus clopidogrel in symptomatic peripheral artery disease. $N$ Engl J Med. 2017;376(1):32-40.

36. Bonaca MP, Bhatt DL, Storey RF, et al. Ticagrelor for prevention of ischemic events after myocardial infarction in patients with peripheral artery disease. J Am Coll Cardiol. 2016;67(23):2719-2728.

37. Cannon CP, Harrington RA, James S, et al; PLATelet inhibition and patient Outcomes Investigators. Comparison of ticagrelor with clopidogrel in patients with a planned invasive strategy for acute coronary syndromes (plato): a randomised double-blind study. Lancet. 2010;375(9711):283-293.

38. Bonaca MP, Bhatt DL, Oude Ophuis T, et al. Long-term tolerability of ticagrelor for the secondary prevention of major adverse cardiovascular events: a secondary analysis of the PEGASUS-TIMI 54 Trial. JAMA Cardiol. 2016;1(4):425-432. 
Drug Design, Development and Therapy

Dovepress

\section{Publish your work in this journal}

Drug Design, Development and Therapy is an international, peerreviewed open-access journal that spans the spectrum of drug design and development through to clinical applications. Clinical outcomes, patient safety, and programs for the development and effective, safe, and sustained use of medicines are the features of the journal, which

has also been accepted for indexing on PubMed Central. The manuscript management system is completely online and includes a very quick and fair peer-review system, which is all easy to use. Visit http://www.dovepress.com/testimonials.php to read real quotes from published authors.

Submit your manuscript here: http://www.dovepress.com/drug-design-development-and-therapy-journal 